\title{
Oviposição dos curculionídeos-das-raízes dos citros (Coleoptera: Curculionidae)
}

\author{
Oviposition characteristics of Citrus root weevils (Coleoptera: Curculionidae)
}

Jerson Vanderlei Carús Guedes ${ }^{1}$ José Roberto Postali Parra ${ }^{2}$

\section{RESUMO}

A oviposição dos curculionídeos-das-raízes dos citros das espécies Naupactus cervinus Boheman, Naupactus versatilis Hustache, Naupactus tarsalis Boheman, Parapantomorus fluctuosus Boheman e Teratopactus nodicollis Boheman foi estudada neste trabalho. Os insetos e os substratos vegetais (frutos, folhas, ramos, solo e resíduos) foram coletados em pomares de laranja, em Itapetininga, SP, e, no laboratório, foram montados seis experimentos, em caixas plásticas, com dimensões de 10,0 × 20,0 × 30,0cm, mantidas à temperatura do ar de $25 \pm 1{ }^{\circ} \mathrm{C}, 60 \pm 10 \%$ de UR e fotofase de $14 \mathrm{~h}$. Foi avaliada a preferência de oviposição por folhas, frutos ou papel parafinado, com livre escolha no experimento A e sem chance de escolha no experimento $B$; preferência por três colorações de frutos (verde, verde amarelado e amarelo) no experimento $C$; três distâncias da casca ao cálice [aderido, intermediário $(\leq 1,5 \mathrm{~mm})$ e distante $(>1,5 \mathrm{~mm})]$ no experimento $D ;$; e por folhas, frutos, solo umedecido ou resíduos vegetais de gramíneas no experimento E. As espécies de curculionídeos-das-raízes dos citros apresentaram diferenças nas características de oviposição. Os curculionídeos-das-raízes dos citros ovipositam em frutos, independentes de sua cor, e em papel parafinado sanfonado. $O$ papel parafinado constitui-se em alternativa para a coleta de ovos em laboratório. Algumas espécies de curculionídeos ovipositam no solo ou em resíduos presentes na superfície do solo.

Palavras-chave: Curculionidae, Naupactus, Parapantomorus, Teratopactus, postura, citros.

\section{ABSTRACT}

The aim of this work was to study some characteristics of oviposition of citrus root weevils. The insects and vegetal substrats (fruits, leaves, branches and debris) were colected in citrus groves, in Itapetininga, SP, Brazil, and conducted to Laboratório de Biologia de Insetos ESALQ/USP, in Piracicaba-SP, Brazil. The species Naupactus cervinus
Boheman, Naupactus versatilis Hustache, Naupactus tarsalis Boheman, Parapantomorus fluctuosus (Boheman) and Teratopactus nodicollis (Boheman) were reared, and the oviposition was observed. Six assays were conducted, all in plastic boxes $(10.0 \times 20.0 \times 30.0 \mathrm{~cm})$, at a $25 \pm 1^{\circ} \mathrm{C}, 60 \pm 10 \% \mathrm{RU}$. The preference was evaluated by leaves, fruits and vax paper, with free choice Assay $A$ and without chance Assay B; preference for three fruit color (green, yellow-green and yellow), at Assay C; three distances from husk to chalice (adhered, intermediate $(\leq 1,5 \mathrm{~mm})$ and far $(>1,5 \mathrm{~mm})$ Assay $D$, and by leaf, fruit and wet soil and vegetal debris Assay D. The species showed differences in oviposition characteristics. They oviposit in fruits with no preference by color and in vax paper. The latter is an alternative for eggs collect at laboratory. Some species oviposit in the soil or in debris at soil surface.

Key words: Curculionidae, Naupactus, Parapantomorus, Teratopactus, oviposition, citrus.

\section{INTRODUÇÃO}

Em algumas regiões produtoras dos estados de São Paulo e de Minas Gerais, os curculionídeosdas-raízes dos citros são considerados pragas primárias da cultura, em virtude dos danos diretos causados pelas larvas ao sistema radicular das plantas e pelos ferimentos que facilitam a entrada de patógenos, tais como Phytophthora spp. (GUEDES et al., 2002).

As espécies de curculionídeos-das-raízes dos citros apresentam ciclos de vida semelhantes (McCOY, 1994). Assim, os adultos recém emergidos migram para a copa das plantas, onde se alimentam das folhas. As fêmeas ovipositam sob o cálice dos frutos e no solo. As larvas eclodem e se desenvolvem no solo onde consomem radicelas, raízes finas e a casca

\footnotetext{
${ }^{1}$ Engenheiro Agrônomo, Doutor em Entomologia, Professor Adjunto, Departamento de Defesa Fitossanitária, Centro de Ciências Rurais, Universidade Federal, de Santa Maria, 97105-900, Santa Maria, RS. E-mail: jerson.guedes@smail.ufsm.br. Autor para correspondência. ${ }^{2}$ Engenheiro Agrônomo, Doutor em Entomologia, Professor Titular, Departamento de Entomologia, Fitopatologia e Zoologia Agrícola, ESALQ, USP.
} 
das raízes mais grossas, até passarem à fase de pupa, ainda no solo e se transformarem em adultos, completando o ciclo (GRAVENA et al., 1992; GUEDES, 2001). No entanto, faltam estudos sobre as características da oviposição dos curculionídeos que ocorrem em citros no Brasil, aspecto essencial ao manejo racional e econômico desse grupo.

As relações entre os aspectos biológicos e a taxonomia de Curculionidae foram primeiramente estabelecidas por Bondar (MUÑIZ, 1970). Para o autor, esse conceito evoluiu até a constatação de uma estreita relação entre o comprimento do rostro dos curculionídeos e o tipo de oviposição que praticam, bem como, com o tipo e local de desenvolvimento larval. As fêmeas dos Curculionidae de rostro curto (Naupactini), colocam seus ovos na face abaxial e adaxial das folhas, protegidos nas dobras dessas folhas ou em fendas presentes na casca da planta (MARVALDI, 1999; LANTERI et al., 2002).

A oviposição dos Curculionidae foi dividida em 11 categorias, baseadas no uso ou não do rostro para a elaboração do local de postura e pela deposição de substância adesiva sobre os ovos. Entretanto, essa classificação não pode ser rígida, devendo variar com a disponibilidade sazonal e a adequação das estruturas vegetais, da enorme diversidade de relações inseto-planta, além da interpretação dos limites de cada categoria (HOWDEN, 1995).

A fase de ovo e o tipo de oviposição de 15 espécies de Curculionidae: Entiminae foram estudadas por MARVALDI (1999), comparando com o estudo de Emden que criou duas grandes categorias de oviposição para essa subfamília. No primeiro grupo (Tipo A Sitona), os ovos são colocados isolados e ao acaso em plantas, resíduos vegetais e/ou no solo; escurecem ou ficam pretos com o desenvolvimento embrionário. No segundo grupo (Tipo B Brachideres), os ovos são depositados em grupo nas folhas, fendas da planta e no solo ou próximo deste, protegidos com uma substância adesiva secretada durante a oviposição. Por sua vez, o autor sugeriu que a separação em dois grupos não pode ser tão rigorosa, pois algumas características que separam as categorias aparecem combinadas em determinadas espécies de Entimini. De forma semelhante, LANTERI et al. (2002) estabeleceram oito tipos de oviposição para os Curculionidae que ocorrem na Argentina; os Naupactini foram colocados em duas categorias, sendo a primeira de insetos que ovipositam em massas aderidas em fendas ou dobras de folhas e outra categoria dos que ovipositam no solo, ambas não utilizando o rostro para elaborar o local de postura.
A oviposição de Naupactus cervinus Boheman, foi estudada por COATS \& McCOY (1990) em citros, no EUA, em plantas acondicionadas em gaiolas teladas, isoladas do solo, pois a espécie fez posturas nesse substrato em um pré-teste. Os frutos concentraram $82,6 \%$ dos ovos, sendo que mais de $99,0 \%$ desses, são colocados sob o cálice; $16,2 \%$ são postos nas folhas e raramente são encontradas posturas nos ramos. A oviposição cresceu em todos os substratos à medida que aumentou o número de insetos, variando de 60,0 a 90,0\% dos ovos nos frutos, para 10 insetos/planta. Em laboratório, LAKIN \& MORSE (1989) estudaram o comportamento de oviposição de $N$. cervinus em dois substratos, observando que as fêmeas realizam postura tanto no fruto quanto no papel de filtro, substratos que foram igualmente aceitos; entretanto a eclosão de larvas foi bastante reduzida nesse último substrato, que sob umidade baixa é ainda mais afetada, atrasando o desenvolvimento embrionário.

O objetivo do trabalho foi estudar algumas características da oviposição das principais espécies de curculionídeos-das-raízes dos citros.

\section{MATERIAL E MÉTODOS}

A oviposição das espécies Naupactus cervinus, Naupactus versatilis, Naupactus tarsalis, Parapantomorus fluctuosus e Teratopactus nodicollis foi analisada em cinco experimentos. Os insetos foram coletados com pano-de-batida com dimensões de 4,0 x 4,0 m e os substratos vegetais utilizados (frutos, folhas, ramos, solo e resíduos de gramíneas) foram obtidos em pomares de laranja com 12 anos de idade, em Itapetininga, SP, em março e abril de 2000 e em outubro de 2001. Os experimentos foram conduzidos no Laboratório de Biologia de Insetos, na ESALQ/USP, em caixas plásticas mantidas em câmara climatizada regulada à temperatura de 25 $\pm 1{ }^{\circ} \mathrm{C}, 60 \pm 10 \%$ de UR e fotofase de 14 horas. Os espécimens foram identificados por Guedes e encontram-se depositados no Museu de Entomologia Agrícola da ESALQ/USP.

No experimento, com livre escolha, a oviposição de $N$. cervinus e $\boldsymbol{P}$. fluctuosus foi avaliada em folhas (dois grupos de duas folhas sobrepostas, unidas pelo pedúnculo), frutos (dois frutos com cálice e pedúnculo) e papel parafinado (seis dobras "sanfonas" medindo 1,0 x 2,5cm), dispostos sobre o fundo das caixas coberto com papel pardo. Cada repetição constava de uma caixa plástica com dimensões de 10,0 × 20,0 × 30,0, com as laterais teladas, onde foram colocados 12 insetos de idade 
desconhecida, por 48 horas. No experimento, sem chance de escolha, cada órgão foi coberto com um copo plástico de $10,0 \mathrm{~cm}$ de altura, onde ficaram contidos dois insetos com as mesmas características do experimento. Ambos os experimentos foram conduzidos no delineamento inteiramente casualizado, com cinco repetições.

No terceiro experimento, com livre escolha, a oviposição de $N$. cervinus, $N$. versatilis e $\boldsymbol{P}$. fluctuosus foi avaliada em frutos de três colorações (verde, verde amarelado e amarelo), dispostos sobre o fundo das caixas coberto com papel pardo, com sete repetições. As avaliações foram idênticas às do segundo experimento. No quarto experimento, com livre escolha, a oviposição de $N$. cervinus, $\boldsymbol{N}$. versatilis e $\boldsymbol{P}$. fluctuosus foi avaliada em frutos com três distâncias da casca ao cálice [aderido, intermediário $(=1,5 \mathrm{~mm})$ e distante $(=1,5 \mathrm{~mm})]$, dispostos sobre um fundo de isopor coberto com papel pardo. No quinto experimento, sem chance de escolha, foram utilizadas as mesmas metodologias dos experimento anterior, também com sete repetições. No sexto experimento, com livre escolha, a oviposição de $N$. versatilis, $N$. tarsalis e $T$. nodicollis foi avaliada em quatro substratos: folha (dois grupos de duas folhas sobrepostas, unidas pelo pedúnculo), dois frutos (com cálice e pedúnculo + folha), solo umedecido (placa de petri plástica com $6,0 \mathrm{~cm}$ de diâmetro) e resíduos vegetais de gramíneas (placa de petri plástica com $6,0 \mathrm{~cm}$ de diâmetro), dispostos sobre o fundo coberto com papel pardo. $\mathrm{O}$ experimento foi conduzido no delineamento inteiramente casualizado com oito repetições constando de uma caixa plástica de 10,0 x 20,0 x $30,0 \mathrm{~cm}$ de comprimento, com as laterais teladas onde foram colocados 16 insetos de idade desconhecida por 48 horas.
Após a exposição dos substratos aos insetos, procedeu-se a contagem dos ovos, os dados de todos os experimentos tabulados e submetidos à análise da variância, sendo as médias comparadas pelo teste de Tukey a de 5\% de probabilidade de erro.

\section{RESULTADOS E DISCUSSÃO}

O número de ovos por fêmea das espécies Naupactus cervinus e Parapantomorus fluctuosus no teste sem chance de escolha, em papel, folhas e frutos cítricos, não foi significativo. Entretanto, no experimento com chance de escolha (Tabela 1), foi significativo para espécies, substratos e espécies $\mathrm{x}$ substratos. Quando não foi dada oportunidade de escolha do local de oviposição não ocorreu diferença entre as espécies $\boldsymbol{N}$. cervinus e $\boldsymbol{P}$. fluctuosus; entretanto, ambas as espécies ovipositaram igualmente nos frutos e na "sanfona" de papel (Tabela 1).

Em laboratório, as espécies não ovipositaram nas folhas de citros, comprovando as observações de campo, onde raramente se verifica oviposição desprotegida. No teste de livre escolha do substrato de oviposição, tanto $\boldsymbol{N}$. cervinus quanto $\boldsymbol{P}$. fluctuosus preferem frutos cítricos a papel para oviposição em laboratório, também não fizeram posturas nas folhas, a despeito de se alimentarem delas (Tabela 1). O comportamento dos curculionídeos-dasraízes dos citros de ovipositarem sobre papel parafinado, colocado nas gaiolas de criação em laboratório, permitiu o uso da "sanfona" para a coleta de ovos de $N$. cervinus, $\boldsymbol{N}$. versatilis e P. fluctuosus. Essa técnica havia sido estudada e adotada por LAKIN \& MORSE (1989) e por COATS \& McCOY (1990) para N. cervinus; assim, mostrou-se eficiente também para os curculionídeos que ocorrem nos citros e possivelmente aplicável para outros Naupactini.

Tabela 1 - Número de ovos ${ }^{1}$ colocados por fêmea de Naupactus cervinus e Parapantomorus fluctuosus em experimento com e sem livre escolha em três substratos: folha, fruto e papel.

\begin{tabular}{|c|c|c|c|}
\hline \multirow{2}{*}{ Espécies } & \multicolumn{3}{|c|}{ Substratos } \\
\hline & Folha & Fruto & Papel \\
\hline \multicolumn{4}{|c|}{ Sem livre escolha } \\
\hline N. cervinus e P. fluctuosus & $0,00 \pm 0,00 \mathrm{~b}^{2}$ & $11,40 \pm 1,62 \mathrm{a}$ & $10,70 \pm 3,89 \mathrm{a}$ \\
\hline \multicolumn{4}{|c|}{ Com livre escolha } \\
\hline Naupactus cervinus & $0,00 \pm 0 \mathrm{~b} \mathrm{~A}$ & $7,20 \pm 2,45$ a B & $0,00 \pm 0 \mathrm{~b} \mathrm{~A}$ \\
\hline Parapantomorus fluctuosus & $0,00 \pm 0 \mathrm{~b} \mathrm{~A}$ & $14,30 \pm 2,05 \mathrm{a} \mathrm{A}$ & $0,00 \pm 0 \mathrm{~b} \mathrm{~A}$ \\
\hline
\end{tabular}

${ }^{1}(\mathrm{X} \pm \mathrm{EP})$ - Médias \pm erro padrão.

${ }^{2}$ Médias não seguidas pela mesma letra minúscula nas linhas (substratos) e maiúscula nas colunas (espécies) diferem entre si pelo teste de Tukey em nível de $5 \%$ de probabilidade. 
A escolha do fruto para oviposição, pelos curculionídeos-das-raízes dos citros, independe da sua cor, devendo estar mais diretamente relacionada à presença de fendas.

Nos experimentos visando avaliar o efeito da distância do cálice à superfície do fruto na oviposição dos curculionídeos-das-raízes dos citros, tanto no teste sem chance de escolha como no de livre escolha, as diferenças foram significativas para espécie e para distância. No experimento sem livre escolha, embora sem apresentar diferença quanto ao número de ovos por fêmea, $\boldsymbol{N}$. cervinus não realizou e $\boldsymbol{N}$. versatilis raramente ovipositou em frutos com o pedúnculo afastado. As maiores médias de ovos/fêmea foram observadas para pedúnculo aderido e intermediário. $\boldsymbol{P}$. fluctuosus ovipositou preferencialmente em frutos com distância intermediária do cálice à superfície do fruto, embora a espécie também tenha feito posturas em frutos com cálice aderido e afastado (Tabela 2). No experimento de livre escolha, as respostas das espécies foram semelhantes ao teste sem chance de escolha, porém somente $\boldsymbol{P}$. fluctuosus fez postura em frutos com o cálice afastado da casca do fruto, caracterizando habilidade da espécie para ovipositar em fendas de diferentes tamanhos (Tabela 3). A alteração da distância entre o cálice e a superfície do fruto envolve dois fatores principais. A característica da variedade em apresentar um cálice grande e aderido torna a fenda adequada à oviposição de alguns Naupactini que ocorrem em citros. Embora a média do número de ovos/fêmea não tenha mostrado diferença entre alturas/distâncias, provavelmente em função da grande variação das mesmas, foi clara a preferência de $N$. cervinus, $N$. versatilis e $\boldsymbol{P}$. fluctuosus em ovipositar em fendas mais estreitas, ou seja, quando o cálice estava mais próximo à casca do fruto. Embora os Naupactini prefiram fendas estreitas (cálice aderido), essas devem ser amplas, o suficiente para permitir que a fêmea introduza o ovipositor distendido, e não serem demasiadamente afastadas a ponto de exporem a postura à dessecação e aos inimigos naturais.

Quanto ao tipo de substrato, N. versatilis, N. tarsalis e Teratopactus nodicollis preferiram ovipositar no solo e em resíduos vegetais (Tabela 4), quando comparados aos frutos, que são estruturas preferidas pelas espécies de porte pequeno, como $N$. cervinus e $\boldsymbol{P}$. fluctuosus. Dentre as espécies que ovipositaram no solo, $N$. versatilis e $N$. tarsalis depositam massas de ovos envoltas por substância

Tabela 2 - Número de ovos ${ }^{1}$ colocados por fêmea de Naupactus cervinus, Naupactus. versatilis e Parapantomorus fluctuosus em experimento sem chance de escolha, com três distâncias de cálice: aderido, intermediário e afastado.

\begin{tabular}{lccc}
\hline \multirow{3}{*}{ Espécies } & \multicolumn{3}{c}{ Distâncias de cálice } \\
\cline { 2 - 3 } & Aderido & Intermediário & Afastado \\
\hline Naupactus cervinus & $8,71 \pm_{2,59 \text { a B }}$ & $4,14 \pm_{2,53}$ a B & $0,00 \pm 0,00$ a A \\
Naupactus versatilis & $5,92 \pm 2,65$ a B & $3,78 \pm_{1,85}$ a B & $0,00 \pm 0,00$ a A \\
Parapantomorus fluctuosus & $17,78 \pm 3,21$ a A & $27,85 \pm 2,21$ a A & $6,64 \pm 3,56$ b A \\
\hline
\end{tabular}

${ }_{1}^{1}(\mathrm{X} \pm \mathrm{EP})$ - Médias \pm erro padrão.

${ }^{2}$ Médias não seguidas pela mesma letra minúscula nas linhas (distâncias de cálice) e maiúscula nas colunas (espécies) diferem entre si pelo teste de Tukey em nível de $5 \%$ de probabilidade.

Tabela 3 - Número de ovos ${ }^{1}$ colocados por fêmea de Naupactus cervinus, Naupactus versatilis e Parapantomorus fluctuosus em experimento com livre escolha de três distâncias de cálice: aderido, intermediário e afastado.

\begin{tabular}{lccc}
\hline & \multicolumn{3}{c}{ Distâncias de cálice } \\
\cline { 2 - 4 } Espécies & Aderido & Intermediário & Afastado \\
\hline Naupactus cervinus & $4,21 \pm_{1,97 \text { a B}^{2}}$ & $6,28 \pm_{3,61 \text { a B }}$ & $0,00 \pm 0,00$ a A \\
Naupactus versatilis & $4,42 \pm 1,79$ a B & $4,00 \pm 1,83$ a B & $1,57 \pm 0,91$ a A \\
Parapantomorus fluctuosus & $18,64 \pm 3,22$ b A & $30,64 \pm_{3,47}$ a A & $7,07 \pm 2,96$ b A \\
\hline
\end{tabular}

${ }^{1}(\mathrm{X} \pm$ EP) - Médias \pm erro padrão.

${ }^{2}$ Médias não seguidas pela mesma letra minúscula nas linhas (distâncias de cálice) e maiúscula nas colunas (espécies) diferem entre si pelo teste de Tukey em nível de 5\% de probabilidade. 
Tabela 4 - Número de $\operatorname{ovos}^{1}$ colocados por fêmea de Naupactus versatilis, Naupactus tarsalis e Teratopactus nodicollis em experimento com livre escolha de quatro tipos de substratos: folha, fruto, solo e resíduos.

\begin{tabular}{lcccc}
\hline & & & Substratos & \\
\cline { 2 - 5 } Espécies & Folha & Fruto & Solo & Resíduo \\
\hline N. versatilis & $3,43 \pm 2,15 \mathrm{c} \mathrm{A}^{2}$ & $3,87 \pm 2,22 \mathrm{c} \mathrm{A}$ & $61,00 \pm 4,20 \mathrm{a} \mathrm{A}$ & $18,81 \pm 3,86 \mathrm{~b} \mathrm{~A}$ \\
$N$. tarsalis & $0,00 \pm 0,00 \mathrm{~b} \mathrm{~A}$ & $0,00 \pm 0,00 \mathrm{~b} \mathrm{~B}$ & $11,62 \pm 1,21 \mathrm{a} \mathrm{B}$ & $8,68 \pm 0,89 \mathrm{a} \mathrm{AB}$ \\
$T$. nodicollis & $0,00 \pm 0,00 \mathrm{~b} \mathrm{~A}$ & $0,00 \pm 0,00 \mathrm{~b} \mathrm{~B}$ & $22,00 \pm 1,45 \mathrm{a} \mathrm{B}$ & $3,00 \pm 0,44 \mathrm{~b} \mathrm{~B}$ \\
\hline
\end{tabular}

${ }^{1}(\mathrm{X} \pm \mathrm{EP})$ - Médias \pm erro padrão.

${ }^{2}$ Médias não seguidas pela mesma letra minúscula nas linhas (substratos) e maiúscula nas colunas (espécies) diferem entre si pelo teste de Tukey ao nível de $5 \%$ de probabilidade.

adesiva e $\boldsymbol{T}$. nodicollis coloca seus ovos isoladamente e sem substância adesiva. A ausência de substância adesiva limita a oviposição, pois os ovos não aderem ao substrato e possivelmente por isso não ocorram na parte aérea da planta.

Algumas espécies de Naupactini colocam os ovos no solo ou na base da planta. A ocorrência de posturas no solo deve estar relacionada a falta, na planta, de locais adequados à postura, como fendas; um outro fator que determinaria a oviposição no solo possivelmente esteja relacionado ao tamanho das espécies, pois espécies grandes $(\geqslant 2,0 \mathrm{~cm})$ não conseguem ovipositar nos frutos (LOIÁCONO \& MARVALDI, 1994; MARVALDI, 1999). Desse modo, a oviposição na parte aérea da planta cítrica deve estar ligada não somente ao tipo de ovipositor (LANTERI et al., 1994), como também ao porte do inseto, uma vez que as espécies maiores, como $N$. tarsalis preferiram e $N$. versatilis também fizeram suas posturas no solo e nos resíduos de gramíneas na superfície do solo, mesmo apresentando ovipositor pouco esclerosado, embora COATS \& McCOY (1990) tenham observado que $N$. cervinus também oviposita no solo, junto ao colo da planta cítrica.

Os curculionídeos-das-raízes dos citros apresentaram características de oviposição variáveis de acordo com a espécie e com a disponibilidade de substrato. Nos frutos, os Naupactini ovipositam independente de sua cor, entretanto preferem aqueles com o cálice próximo à casca, além de ovipositarem no solo ou em resíduos presentes na sua superfície. A característica dos curculionídeos-das-raízes dos citros de ovipositarem em frestas nos frutos (sob o cálice), no solo e em resíduos de vegetais na superfície do solo, representa uma grande diversidade de comportamentos relacionada ao tamanho da espécie, tipo de ovipositor e a disponibilidade de substrato, entretanto, em todos as espécies, as fêmeas visam proteger a postura de inimigos naturais e das adversidades climáticas, tornando sua observação em campo mais difícil, especialmente para a quantificação populacional.

\section{REFERÊNCIAS BIBLIOGRÁFICAS}

COATS, S.A.; McCOY, C.W. Fuller rose beetle (Coleoptera: Curculionidae) ovipositional preference on Florida citrus. Journal of Economic Entomology, v.83, n.3, p.860-865, 1990.

GRAVENA, S. et al. Pantomorus e Naupactus uma ameaça à citricultura. Jaboticabal : FUNEP, 1992. 9p. (Boletim Técnico, 2).

GUEDES. J.V.C. Guia de identificação das pragas dos citros. Santa Maria : Departamento de Defesa Fitossanitária, 2001. 60p.

GUEDES, J.V.C.; PARRA, J.R.P.; YAMAMOTO, P.T. Ocorrência de curculionídeos-das-raízes dos citros em São Paulo. Laranja, v.23, n.2, p.308-320, 2002.

HOWDEN, A.T. Structures related to oviposition in Curculionoidea. In: ANDERSON, R.S.; LYAL, C.H. (eds.). Biology and phylogeny of Curculionoidea. Washington : Memoirs Entomology Society of Washington, 1995. V.14, p.53-100.

LAKIN, K.R; MORSE, J.G. A degree-day model for fuller's rose beetle, Pantomorus cervinus (Boheman) (Col., Curculionidae) egg hatch. Journal Applied Entomology, v.107, p.102-106, 1989.

LANTERI, A.A.; DÍAZ, N.B.; MORRONE, J.J. Identificación de las especies. In: LANTERI, A.A. (Ed.). Bases para el control integrado de los gorgojos de la alfalfa. La Plata : De la Campana, 1994. Cap.1, p.3-40.

LANTERI, A.A.; MARVALDI, A.E.; SUÁREZ, S. Gorgojos de la Argentina y sus plantas huéspedes. Tomo I: Apionidae y Curculionodae. Tucumán : SEA, 2002. 98p.

LOIÁCONO, M.S.; MARVALDI, A.E. Biologia y daños ocasionados. In: LANTERI, A.A. (Ed.). Bases para el control integrado de los gorgojos de la alfalfa. La Plata : De la Campana, 1994. Cap.3, p.49-55.

MARVALDI, A.E. Eggs and oviposition habits in Entimini (Coleoptera: Curculionidae). Coleopterists Bulletin, v.53, p.115126. 1999.

Ciência Rural, v.34, n.3, mai-jun, 2004. 
McCOY, C.W. Besouros da raiz dos citros: biologia e estratégias atuais de MIP na Flórida. In: DONADIO, L.C.; GRAVENA, S.

(Ed.). Manejo integrado de pragas dos citros. Campinas : Fundação Cargill, 1994. Cap.1, p.233-254
MUÑZ, R.V. Relación entre taxonomía y tipos de vida en Curculionidae. Annales de la Escuela Nacional de Ciencias Biológicas, v.17, p.169-187, 1970 .

Ciência Rural, v.34, n.3, mai-jun, 2004. 